\title{
Mapeamento das delegacias especializadas da mulher da Paraíba: percepção dos funcionários em relação à lei Maria da Penha
}

\section{Mapping of the specialized police station for women in Paraíba: perception of employees in relation to Maria da Penha law}

\author{
Julyana de Araújo Oliveira1, Patrícia Moreira Rabello², Alice Villar Aquino de Carvalho², \\ Maria do Socorro Dantas de Araújo4.
}

\begin{abstract}
Oliveira JA, Rabello PM, Carvalho AVA, Araújo MSD. Mapeamento das delegacias especializadas da mulher da Paraíba: percepção dos funcionários em relação à lei Maria da Penha. Saúde, Ética \& Justiça. 2011;16(2):86-92.

RESUMO: Objetivo: Estudar o Mapeamento dos funcionários das Delegacias Especializadas da Mulher (DEM) e a percepção em relação à Lei Maia da Penha. Metodologia: Pesquisa quanti-qualitativa, realizada nos municípios paraibanos que possuem DEMs. A amostra foi composta por 30 funcionários, sendo os instrumentos utilizados formulário e entrevistas a respeito da Lei Maria da Penha registradas por $\mathrm{mp3}$, as quais foram transcritas e analisadas utilizando a Técnica Discurso do Sujeito Coletivo (DSC). Resultado: A Lei Maria da Penha é importante para inibir a violência contra a mulher. A mesma aumentou o trabalho nas Delegacias porque transformou a forma processual em inquérito policial, no entanto as vítimas desistiam de continuar o procedimento, por serem dependentes emocional e financeiramente do companheiro. Conclusão: Os pesquisados acreditam que a Lei deva ser aplicada de maneira mais efetiva pelo Estado, procurando prestar atendimento completo às vítimas de violência, desde abrigo até recuperação da família envolvida no processo.
\end{abstract}

DESCRITORES: Violência doméstica/legislação \& jurisprudência; Violência contra a mulher, Legislação como assunto/ organização \& administração.

O texto é inédito. Resultado de monografia apresentada ao Curso de Especialização em Odontologia Legal. Aprovado por parte do Comitê de Ética e Pesquisa da Universidade Federal da Paraíba CEP-CCS, no dia 18/05/2009, protocolo $\mathrm{n}^{\circ} 0132$.

1. Graduada em Odontologia pela Universidade Federal da Paraíba.

2. Professora Doutora Adjunta do Departamento de Clínica e Odontologia Social da UFPB.

3. Especialista em Odontologia Legal pelo Centro Odontológico de Estudos e Pesquisas (COESP).

4. Gerente Executiva do GEMOL - Gerência Executiva de Medicina e Odontologia Legal.

Endereço para correspondência: Julyana de Araújo Oliveira. Endereço: Rua Antônio Luna Lisboa, nº 47, Bairro: Cristo Redentor, João Pessoa, PB. CEP: 58071-025. E-mail: julyana86@ hotmail.com 


\section{INTRODUÇÃO}

$\mathrm{S}$ egundo Penna et al. ${ }^{13}$, ainda é recente a projeção do tema violência doméstica no mundo acadêmico como fenômeno social, sendo a mesma concebida por meio de variadas formas interpessoais (agressão física, abuso sexual, psicológico e negligência) as quais ocorrem no seio da família e são perpetradas por um agressor que geralmente possui laços de parentescos familiares ou conjugais.

Desde o final da década de 1970, a referida temática é uma das prioridades dos movimentos feministas no Brasil. Sendo assim, o processo de institucionalização das demandas feministas nesta área pode ser identificado por três momentos estratégicos: A criação das delegacias da mulher, em meados dos anos 1980, o surgimento dos Juizados Especiais Criminais, nos anos de 1990, e o advento da Lei 11.340, a chamada Lei "Maria da Penha", em 2006 ${ }^{15}$.

Com a criação da Lei Maria da Penha (Lei no. 11.340), surgiram mecanismos para coibir a violência doméstica e familiar contra a mulher, nos termos do § 8음 art. 226 da Constituição Federal, da Convenção sobre a eliminação de todas as formas de discriminação contra as mulheres e da Convenção Interamericana para prevenir, punir e erradicar a violência contra a mulher. Esta Lei ainda dispõe sobre a criação dos Juizados de Violência Doméstica e Familiar contra a Mulher e altera o Código de Processo Penal, o Código Penal e a Lei de Execução Penal ${ }^{4}$.

$\mathrm{Na}$ citada Lei, Capítulo II, Artigo 9, a assistência à mulher em situação de violência doméstica e familiar deve ser prestada de forma articulada, conforme os princípios e as diretrizes previstos na Lei Orgânica da Assistência Social, no Sistema Único de Saúde e no Sistema Único de Segurança Pública, entre outras normas e políticas públicas de proteção, e emergencialmente quando for o caso ${ }^{9}$.

Segundo Cavalcanti ${ }^{5}$, a Lei Maria da Penha procura ainda atenuar as desigualdades, como ocorre na maioria dos casos de violência doméstica em que é flagrante a situação de vulnerabilidade da vítima em relação ao agressor. De acordo com Silva ${ }^{16}$, esta Lei deve também promover campanhas educativas, como medidas de prevenção e conscientização dos operadores do direito, acadêmicos e policiais, bem como, de assistência às vítimas de violência.

É notável que o Brasil tem avançado em relação à criação de novas instituições de atenção às mulheres vítimas de violência e ainda com a criação da Lei Maria da Penha, imagina-se que as mesmas estejam possivelmente protegidas na ação de prevenção e proteção contra agressores. No entanto, é necessário observar com cautela se realmente a Lei 11.340 tem auxiliado a prática de combate à violência de gênero. Sendo assim, o referido estudo objetiva levantar dados sob o ponto de vista dos atores envolvidos que trabalham nas Delegacias Especializadas, avaliando a percepção que os mesmos têm em relação à Lei Maria da Penha e, conseqüentemente, à resolutividade dos processos que envolvem a violência contra a mulher.

\section{METODOLOGIA}

Trata-se de uma pesquisa de Campo e Exploratória, com uma abordagem quantiqualitativa. O estudo de campo objetiva principalmente a observação dos fatos que ocorrem naturalmente, utilizando variáveis que sejam importantes, para servir de parâmetros em investigações posteriores. O tipo de pesquisa exploratória, de acordo com Andrade ${ }^{1}$, é aquela em que se dá o primeiro passo de todo trabalho científico, sobretudo, quando a bibliografia proporciona maiores informações sobre determinado assunto, facilitando, assim, a delimitação de um tema de trabalho.

A coleta de dados foi realizada nos sete municípios paraibanos que possuem Delegacias Especializadas da Mulher (João Pessoa, Cabedelo, Campina Grande, Guarabira, Patos, Souza e Cajazeiras). Tais delegacias são subordinadas às Superintendências Regionais de Policia Civil e fazem parte da Secretaria da Segurança e da Defesa Social, sendo a pesquisa autorizada pelo Superintendente Regional de Polícia Civil da Paraíba.

O universo foi composto de 41 funcionários das sete Delegacias Especializadas da Mulher da Paraíba e a amostra, por 30 funcionários públicos que estavam trabalhando ativamente nas referidas instituições e concordaram em participar da pesquisa. Foram excluídos do estudo 11 funcionários por critérios específicos, dentre os quais estão a licença médica, o falecimento 
em família, além de recusa à participação do estudo. Ainda foi descartada a participação dos indivíduos que se prestaram ao desenvolvimento do estudo piloto, o qual objetivou a calibração dos instrumentos da pesquisa.

Para a coleta de dados, utilizou-se um formulário e uma entrevista semi-estruturada, registrada por meio de um aparelho Mp3. O primeiro observou a descrição sócio-demográfica dos pesquisados como sexo, idade, estado civil, escolaridade, formação profissional, renda pessoal e familiar, além de função desempenhada na delegacia. A entrevista semi-estruturada, por sua vez, caracteriza-se pela combinação de perguntas estruturadas e abertas, nas quais o entrevistado tem a possibilidade de discorrer sobre o tema proposto, sem respostas ou condições prédefinidas pelo pesquisador ${ }^{10}$. Tal instrumento de coleta buscou avaliar a percepção dos atores envolvidos quanto a Lei Maria da Penha através de questionamentos estrategicamente elaborados.

Os dados sócio-demográficos foram analisados à luz da estatística descritiva, sendo processados por meio do programa Statistical Package for the Social Sciences (SPSS), versão 13.0 Windows. Para o tratamento dos dados qualitativos advindos das entrevistas semiestruturadas, adotou-se a técnica de análise do Discurso do Sujeito Coletivo (DSC) a qual consiste num conjunto de procedimentos de tabulação e organização de dados discursivos que envolvem as seguintes operações sobre os discursos coletados: seleção das expressões-chave de cada discurso particular; identificação das idéias central, centrais semelhantes e complementares de cada uma das expressões-chave e ainda Reunião das expressões-chave referentes às idéias centrais semelhantes ou complementares em um discurso síntese tabulado em quadro, que caracteriza o Discurso do Sujeito Coletivo (DSC).

O referido estudo seguiu a resolução 196/96 que regulamenta a pesquisa envolvendo seres humanos e foi submetido ao Comitê de Ética na Pesquisa do Centro de Ciências da Saúde da Universidade Federal da Paraíba, sendo aprovado por unanimidade na Reunião do dia 18 de maio de 2009 , tendo o protocolo número 0132. A entrevista só foi efetuada mediante assinatura do Termo de Consentimento Livre e Esclarecido através do qual os voluntários tornaram-se cientes dos objetivos e benefícios da pesquisa, além dos critérios éticos inerentes às pesquisas que envolvem seres humanos.

\section{RESULTADOS E DISCUSSÃO}

Quantoacaracterizaçãosócio-demográfica da amostra, verificou-se que os funcionários na sua maioria eram do sexo feminino $(80,0 \%)$, a faixa-etária mais prevalente foi de 36 a 45 anos $(36,7 \%)$ e metade dos entrevistados acusou-se solteiro. Observou-se ainda, no que diz respeito à escolaridade, que $33,4 \%$ dos pesquisados possuíam Ensino Médio completo, 30,0\% cursaram até a graduação, $13,3 \%$ fizeram aperfeiçoamento e $20,0 \%$ especialização, totalizando $63,3 \%$ de graduados com Ensino Superior completo. Dos que fizeram curso superior $30,0 \%$ cursaram direito, existindo apenas um Assistente Social e um psicólogo nos quadros das Delegacias. De acordo com Azevedo $^{2}$, seria adequado lidar com o conflito da violência doméstica fora do sistema penal, aplicando o mecanismo de mediação realizada por pessoas devidamente treinadas a despeito dos profissionais da Psicologia e Assistência Social. Em relação a tais classes profissionais, as DEMs do Estado demonstraram-se deficientes no que se refere a esse tipo de recurso humano especializado, contribuindo para um déficit da qualidade do serviço prestado.

A renda pessoal caracterizou-se pela prevalência entre três a quatro salários mínimos $(30,0 \%)$ e a familiar entre 10 salários mínimos e acima $(43,3 \%)$. Vale salientar que não houve queixa a respeito dos salários recebidos, o que indica ainda uma valorização do emprego público nos últimos anos no Brasil, sendo demonstrada pelo crescente número de candidatos a cada concurso da Polícia Civil paraibana. No que concerne à função desempenhada na DEM, 36,7\% dos funcionários eram Agentes de Investigação, $23,3 \%$ eram Delegadas e $20,0 \%$, Escrivães de Polícia.

No Quadro 1, referente ao DSC a respeito da Lei 11.340, os participantes exprimiram a idéia de que a Lei Maria da Penha seria muito eficiente se fosse cumprida na íntegra e não ficasse resumida ao ato da queixa na Delegacia. Segundo tais funcionários, houve uma diminuição do número de ocorrências uma vez que as vítimas têm preferido não dar continuidade aos processos pela falta da assistência do Estado presumida na Lei, como a garantia das casas de abrigo, associada à possível ineficiência das medidas protetivas. 
Oliveira JA, et al. Mapeamento das delegacias especializadas da mulher da Paraíba.

Quadro 1. Expressões-chaves, Idéia central e Discurso do Sujeito Coletivo dos participantes em resposta: "O que você acha da lei Maria da Penha?" Paraíba - Brasil, 2009

\section{EXPRESSÕES-CHAVES}

(1) Lei moderna, porém falha, (2) Momentos diferentes, (3) Utopia, (4) Lei apenas para a Delegacia

\section{IDEIA CENTRAL}

(1) "Ela é uma lei muito moderna, a questão da família, como é que trata a família, o atendimento a vítima, mas ainda existem muitas falhas, inclusive aqui ainda não tem nem o Juizado ainda".

(2) "No primeiro momento da Lei Maria da Penha, tirou-se da vítima a responsabilidade de decidir ou não por esse procedimento, então nós tivemos muitos procedimentos policiais... agora do STJ e devolveu à vítima a responsabilidade de decidir se quer ou não o procedimento por esse tipo de crime que é agressão. E o que acontece é que elas estão deixando de representar".

(3) "Eu acho que ela é utópica porque ela realmente trouxe muito benefícios, mas que na prática são muito difíceis de se executar. Assim... a lei ela prevê que a mulher que tá sendo agredida ela vai pra um abrigo. E aí? Onde é que tem esse abrigo?! Como ela vai depois se sustentar? Eu acho que o Estado ele não oferece a capacitação pra que essa mulher ela entre no mercado de trabalho, e ela tenha realmente coragem... de acabar com o sofrimento que ela tem. Então falta muito ainda pro país ter uma condição social pra que essa lei seja aplicada".

(4) “... no interior, a lei Maria da Penha ficou apenas com a Delegacia da Mulher mal equipada, como único equipamento disponível pra vítima. Então esse é o problema da Lei Maria da Penha”.

\section{DISCURSO DO SUJEITO COLETIVO}

É uma Lei recente e importante para inibir a violência contra a mulher. No início houve muitos procedimentos policiais, porém atualmente, a vítima tem preferido não dar prosseguimento as denuncias, pois não tem assistência do Estado, o que diminuiu o número de ocorrências. Seria uma Lei muito eficiente se fosse cumprida na íntegra e não ficasse resumida às Delegacias.

Nobre $^{12}$, menciona que após a criação da Lei Maria da Penha, a experiência de Mediação de Conflitos foi interrompida, pois esta Lei restituiu as unidades policiais às atribuições de investigação e repressão. Inúmeros estudos sobre a violência de gênero e as ações das Delegacias da Mulher, revelam que, durante 20 anos, 0 atendimento às mulheres em situação de violência começava, em geral, com um pedido de informações visando ao registro de um Boletim de Ocorrência e terminava em uma audiência com a delegada ou atendimento de natureza psicossocial. No caso da separação conjugal, havia outras expectativas das mulheres, voltadas à garantia de direitos, como pagamento de pensão e partilha de bens ${ }^{2}$.

Em relação às transformações ocorridas no atendimento às mulheres vítimas após - advento da Lei, os entrevistados relatam o aumento do trabalho nas delegacias paraibanas em virtude da mudança da forma processual, pois o que antes era um procedimento simplificado através de um Juizado Especial conciliador deu lugar aos procedimentos de inquérito policial. No entanto, segundo os pesquisados a demanda sofreu variações: No primeiro momento houve aumento de queixas prestadas e instauração de inquéritos. Porém como as vítimas ficaram sem os "provedores" quando estes eram presos em flagrante, desistiam de continuar o procedimento na justiça, que estabelecia a pena do acusado.

Segundo Debert e Gregori ${ }^{7}$, na primeira década de criação das delegacias especializadas, uma das críticas mais contundentess dirigida às delegacias da mulher estava relacionada ao número elevado de boletins de ocorrência que não se transformava em denúncias encaminhadas para o Ministério Público e, portanto, ao fato de as vítimas continuarem a ter acesso reduzido à justiça, prejudicando do atendimento prestado nessas instituições. Atualmente, segundo os entrevistados, a resolutividade da Lei tem apresentado melhoras nos casos mais graves, em decorrência das medidas protetivas como a prisão ou afastamento imediato do agressor ao lar, porém não há uma rede de informações entre as demais instituições que lidam com a violência de gênero (como os Fóruns Criminais) e as Delegacias Especializadas, dificultando assim a percepção da eficácia da 
aplicação da Lei por parte dos funcionários que lidam com a violência no âmbito das delegacias.

Para Debert e Oliveira $^{8}$, apesar da resolutividade da Lei Maria da Penha sendo o agressor autuado em flagrante, a audiência de conciliação realizada nos Juizados Especiais Criminais (JECrim) pode ser transformada num espaço privilegiado para a indução das vítimas a desistirem da causa levada à Justiça. Na etapa da conciliação se torna possível a acolhida e, ao mesmo tempo, a retirada da queixa de violência doméstica do Judiciário. As pesquisas sobre os JECrim apontam que a maioria dos crimes que entram neste procedimento conciliatório não se transforma em processo penal. Tais pesquisadores relatam ainda que a indução à não-representação é uma forma de retirar, definitivamente, o caráter propriamente criminoso dos crimes que ocorrem no espaço doméstico. Os casos enviados pelas Delegacias da Mulher para os Juizados são caracterizados pelos seus agentes como de caráter mais "social" do que "criminal". Nesse sentido, os acusados não seriam propriamente criminosos, o que por sua vez, limita a resolutividade da Lei $n^{\circ}$. 11.340 .
O Quadro 2, relativo à conseqüência da Lei Maria da Penha para a vítima, demonstra uma situação bastante freqüente nos depoimentos dos entrevistados. Tal situação reafirma uma das principais dificuldades do combate à violência de gênero, a qual caracteriza-se pela dependência emocional e financeira da mulher agredida em relação ao agressor. Para Brandão $^{3}$, a ida à Delegacia Especializada da Mulher envolve a esperança de "resolver alguma coisa" ou de propiciar uma ocasião para amedrontar o parceiro quanto às possíveis implicações de uma próxima agressão, pelo fato de ele já estar envolvido como suspeito em uma ocorrência. Assim, imensas expectativas são depositadas no recurso à DEM, na possibilidade de a intervenção policial conter o acusado. Tais expectativas são consideradas vagas pelos policiais, que encontram dificuldades em transmutá-las para os termos penais previstos na Lei $n$ o. 11.340. Ao reivindicarem determinadas medidas "corretivas" contra os parceiros, as mulheres não buscam uma punição específica àquele delito denunciado, mas a restauração de toda uma ordem que confere sentido não só àquela relação, mas à sua existência social.

Quadro 2. Expressões-chaves, Idéia central e Discurso do Sujeito Coletivo dos participantes em resposta: "Qual a conseqüência desta lei para a vítima?" Paraíba - Brasil, 2009

EXPRESSÕES-CHAVES: (1) Paz, (2) Sozinha

IDEIA CENTRAL

(1) "Para a vítima, ela poder prender seu agressor. Mesmo que ele não fique muito tempo preso, dá um espaço de tempo para que ela arrume suas malas, saia da casa, né, se retire, se sinta um pouco de paz".

(2) "Só que se tira o agressor de dentro de casa, mas ela não tem nenhuma fonte de renda e não é arbitrada uma pensão de alimentos, retiraram simplesmente o sustento de casa e ela vai se sujeitar a recebê-lo, porque ela não foi colocada em lugar nenhum. Eu costumo dizer que quando a minha vítima sai daqui de dentro, quando ela chega na calçada da delegacia, ela tá só de novo, ela está novamente só. Então, para a vítima, qual a conseqüência da lei pra vítima? Se a lei fosse absolutamente implementada, mudaria a vida da vítima, pelo menos num bom percentual das vítimas. Mas hoje, só cobre ela no momento do incêndio, mas num momento posterior, poucas vítimas se aproveitam do que ela traz, de fato".

\section{DISCURSO DO SUJEITO COLETIVO}

Por conta das medidas protetivas o agressor é preso e a vítima tem paz no pior momento da agressão. Todavia, posteriormente ela o aceita novamente, pois é dependente emocionalmente e financeiramente do companheiro.

Segundo estudo realizado por Marinheiro et al. ${ }^{11}$, apesar das mudanças promovidas pela promulgação da Lei Maria da Penha, apenas uma parcela das mulheres reconhece a violência, sendo esta invisível para muitas delas. Embora 45,3\% tenham relatado ocorrência de violência pelo menos uma vez na vida, apenas a metade $(22,3 \%)$ reconhece o que lhes ocorreu como violência. Por outro lado, para Dantas-Berger e Giffin", as "novas mulheres" não mais se adequam às representações tradicionais que colocariam como destino feminino "agüentar" situações de objetificação e 
violência, para que o casamento (e o seu próprio reconhecimento social como sujeito moral) fosse mantido. São avanços claros, se comparados às pesquisas sobre violência doméstica realizadas há cerca de vinte anos.

O Quadro 3 demonstra O DSC relativo ao grau de satisfação do serviço prestado na instituição depois da Lei Maria da Penha. De forma geral o funcionário analisado se sente bem em trabalhar na Delegacia da Mulher da Paraíba. No entanto, é destacado o relato das dificuldades de infra-estrutura e falta de Recursos Humanos no Serviço. As Delegadas do interior do Estado das cidades de Patos, Sousa e Cajazeiras citam que as delegacias trabalham com a mulher vítima e agressora, descaracterizando a função da Delegacia Especializada, de dar assistência à mulher vítima de violência doméstica e familiar ou de gênero, aumentando outros tipos de procedimentos e desqualificando o serviço por conseqüência.

Quadro 3. Idéia central e Discurso do Sujeito Coletivo dos participantes em resposta: "Qual o seu grau de satisfação com o serviço prestado depois desta lei?" Paraíba - Brasil, 2009

\section{EXPRESSÕES-CHAVES}

(1) satisfação, (2) falta Infra-estrutura, (3) falta Recursos Humanos

\section{IDEIA CENTRAL}

(1)“Estou satisfeita com o trabalho aqui na delegacia da mulher e poder ajudar a pessoa que chega com problema”.

(2)“Pelo serviço prestado eu acho que no geral a gente tá precisando ainda de mais capacitação, infra-estrutura, mas assim, a gente vê que o pessoal tem bom gosto e tem boa vontade de fazer".

(3)“...nós não temos uma equipe multidisciplinar, é... psicólogo, assistente social, pessoas que nos ajudem. Temos um apoio, um certo apoio do Conselho Tutelar, o Conselho Tutelar nos apóia de certa maneira, com a casa de menores lá... é... também temos um certo apoio do Ministério Público, mas é muito frágil, a gente se sente assim meio perdida, e ainda tem um fator que atrapalha demais, porque as Delegacias Especializadas do interior da Paraíba, ela não trabalha só com violência contra a mulher, violência de gênero. Ela trabalha com tudo o que se refere à mulher, seja ela vítima ou acusada".

\section{DISCURSO DO SUJEITO COLETIVO}

De forma geral o funcionário se sente bem em trabalhar na Delegacia da Mulher. No entanto, destacam-se as dificuldades de infra-estrutura e falta de recursos humanos no serviço. No interior da Paraíba as Delegacias trabalham com a mulher vítima e agressora, descaracterizando a função da Delegacia Especializada.

Detectou-se no decorrer do estudo que as Delegacias Especializadas da Mulher de Cajazeiras, Guarabira e Souza são instaladas juntamente com outras Delegacias Distritais. Nesses casos, as Delegacias de Cajazeiras e Souza possuem espaços bem pequenos e ainda contam com poucos funcionários. De forma geral, ainda há uma quantidade pequena de recursos materiais como viaturas e demais equipamentos bem como de estrutura física para um melhor atendimento às vítimas. Rifiotis ${ }^{14}$, pesquisando a Delegacia Especializada de João Pessoa a partir do ano de 1999, constatou precariedade de instalações e de formação profissional, corroborando o discurso síntese dos participantes.

\section{CONCLUSÃO}

Nas duas décadas de criação das Delegacias Especializadas das Mulheres no Brasil, muitos avanços ocorreram. Inclusive, uma maior conscientização e discussão por parte da população a respeito desta complexa rede que envolve a violência doméstica familiar e de gênero. No entanto, muitas medidas precisam ser efetivadas, para que a mulher maltratada tenha uma assistência acolhedora, como a preconizada na Lei Maria da Penha. Na luta pelos direitos humanos, uma mudança nas relações de gênero só acontecerá com a reversão das desigualdades econômico-sociais e a inserção da mulher nos programas de habitação e mercado de trabalho, através de uma perspectiva emancipadora, voltada para a recuperação social das mulheres.

Para fomentar um serviço mais eficiente e suprir a rede complexa da violência doméstica seria necessária uma educação permanente de todos os funcionários que lidam com vítimas e agressores, além de melhorias quanto à infra-estrutura, recurso humano qualificado e equipamento disponíveis nas Delegacias Especializadas da Mulher da Paraíba. 
Oliveira JA, Rabello PM, Carvalho AVA, Araújo MSD. Mapping of the specialized police station for women in Paraíba: perception of employees in relation to Maria da Penha law. Saúde, Ética \& Justiça. 2011;16(2):86-92.

ABSTRACT: Aim: Study the mapping of employees from the specialized precincts for women (DEMs) and their perception of the Maria da Penha law. Methodology: Quantitative-qualitative study conducted in municipalities of Paraiba that have DEMs. The sample was composed of 30 employees and the instruments used were a form and interviews related to the Maria da Penha law, which were recorded on MP3 and transcribed and analyzed using the Discourse of the Collective Subject. Result: The Maria da Penha Law is important for protecting women against violence. It has led to an increased work load at the precincts because it transformed a civil process into a police inquiry. In general, the employees enjoyed working at the DEM; however, there are human resource and infrastructure problems. Conclusion: The study subjects believe that the law should be enforced more effectively by the state, by providing comprehensive assistance to victims of violence, including shelter and counseling to the families involved in the process.

KEYWORDS: Domestic violence/legislation \& jurisprudence; Violence against women, Legislation as topic/organization \& administration.

\section{REFERÊNCIAS}

1. Andrade MA. Introdução à metodologia do trabalho científico. 6a ed. São Paulo: Atlas; 2003.

2. Azevedo RG. Sistema penal e violência de gênero: análise sociojurídica da Lei 11.340/06. Soc Estado. 2008;23 (1):113-35.

3. BrandãoER. Renunciantes de direitos? A problemática do enfrentamento público da violência contra a mulher: o caso da Delegacia da Mulher. Rev Saúde Coletiva Rio de Janeiro. 2006;16 (2):207-31.

4. Brasil. Congresso Nacional. Lei Maria da Penha $n$. 11.340/06. Brasília; 2006.

5. Cavalcanti SVSF. Denúncia em crime de violência doméstica. Lei Maria da Penha Jus Navegandi. 2007;11(1383) [citado 19 fev. 2009]. Disponível em: http://jus2.uol.com.br/pecas/texto.asp?id=760.

6. Dantas-Berger SM, Giffin K. A violência nas relações de conjugalidade: invisibilidade e banalização da violência sexual?. Cad Saúde Pública, Rio de Janeiro. 2005;21(2):1-10.

7. Debert GG, Gregori MF. Violência e gênero: novas propostas, velhos dilemas. Rev Bras Cien Soc, São Paulo. 2008;23(66):5-10.

8. DebertGG, OliveiraMB. Domestic violenceand different forms of conciliation. Cad Pagu. 2007. Disponível em: http://www.scielo.br/scielo.php?script=sci_arttext\&pid $=$ S010483332007000200013\&lng $=$ en \&nrm=iso.

9. Hermann LM. Maria da Penha lei com nome de Mulher: violência doméstica e familiar. Considerações à Lei no 11.340/2006 comentada artigo por artigo. Campinas,
SP: Servanda Ed.; 2008.

10. Lefévre F, Lefévre AMC, Teixeira JJV. O discurso do sujeito coletivo: uma nova abordagem metodológica em pesquisa qualitativa. Caxias do Sul: EDUCS; 2000.

11. Marinheiro ALV, Vieira LS. Prevalência da violência contra a mulher usuária de serviço de saúde. Rev Saúde Pública. 2006;40(4):604-10.

12. Nobre MT, Barreira C. Controle social e mediação de conflitos: as delegacias da mulher e a violência doméstica. Sociologias. 2008;2(20):138-63.

13. Penna LHG, Santos NC, Souza ER. A produção científica sobre violência doméstica na área da saúde pública. Rev Enferm UFRJ. 2004;12(2):192-8.

14. RifiotisT. As delegacias especiais de proteção à mulher no Brasil e a «judiciarização» dos conflitos conjugais. Soc Estado. 2004;19(1):85-119.

15. Santos CM. Da Delegacia da Mulher à Lei Maria da Penha: lutas feministas e políticas públicas sobre violência contra mulheres no Brasil. Oficina do CES 301, mar. 2008 [citado 21 dez. 2009]. Disponível em: https://estudogeral.sib.uc.pt/dspace/ bitstream/10316/11080/1/Da\%20Delegacia\%20 da\%20mulher\%20\%c3\%a0\%20Lei\%20Maria\%20 da\%20Penha.pdf.

16. Silva SM. Violência doméstica na Lei Maia da Penha. Reflexos da visibilidade jurídica do conflito familiar de gênero. Jus Navigandi. 2008;12(1874):130-40 [citado 9 fev. 2009]. Disponível em: http://jus2.uol.com.br/ doutrina/texto.asp?id=11614. 